The Experimental Study of Structures By Prof. A. J. S. Pippard. Pp. viii +114. (London : Edward Arnold and Co., 1947.) 9s. net.

7 HIS book is based "on a course of lectures given by Prof. A. J. S. Pippard to teachers in technical colleges on the use of models in the teaching of the theory of structures. After a discussion of the function of experiments in structural teaching and research and a brief summary of certain fundamental theorems, Prof. Pippard limits himself, in spite of the rather sweeping title of the book, to a description of the equipment and teaching programme of the excellent Model Structures Laboratory at the Imperial College. Chapters follow on direct experimental methods, applications of the reciprocal theorem, strain energy and moment distribution methods, experiments on voussoir arches and experiments with sand.

Prof. Pippard makes out a very strong case for the use of models in teaching, but many will feel that he overstates it when he suggests that in the absence of the experimental approach there is a tendency "to regard the subject as merely one more course of lectures in mathematics". There is very little doubt that demonstrations add greatly to the entertainment value of a lecture and the popularity of a lecturer, but by their very nature they are bound to falsify the behaviour of real structures, and may easily mislead.

The chapter on Begg's method and the method of large deflexions should make these valuable tools of the structural designer much more widely known. It is surprising that no mention is made of the creep properties of celluloid, which is the model material used. The fact that celluloid has an instantaneously constant value of Young's modulus is an essential condition for the success of this method of analysis.

Prof. Pippard concludes his book with a number of practical hints which should prove most useful to all those who will be encouraged by it to teach experimental methods of structural analysis in universities and technical colleges. E. K. FRANKL

Mathematical Aids for Engineers

By Raymond W. Dull. Pp. xii + 346. (New York and London: MeGraw-Hill Book Co., Inc., 1946.) 22s. $6 d$.

T HE necessity for this book is well stated by the author when he declares in the preface: "There have been so many new engineering developments in the last few years that engineers and those preparing to become engineers are seeking mathematical aids to meet the situation". Herein lies one of the prime causes for the modern demand that mathematics must become more practical. With the rapid growth of science and the advance in all branches of engineering, the need for the intelligent application of mathematical principles has become urgent. Unfortunately, such application cannot be easily culled from the usual school and college text-books, for they have much too great a bias for theory and, as a consequence, new books are constantly being called for which lay special stress on the practical aspect of the subject. Such books are no longer of the former rule-ofthumb type, nor of the older practical mathematics brand where the treatment had very little, if any, theoretical background; but, to provide for existing needs, mathematical fundamentals are served up with just as much theory as will make them intelligently palatable.
The present work consists of 346 pages of very practical text involving 28 chapters. There are interesting and instructive discussions on scales, logarithms as an implement, organic growth, circles as tools, vectors and the elements of mechanics, and complex numbers, with a brief revision of the fundamentals of the calculus up to practical linear differential equations.

The text is well written and arranged, profusely illustrated both with clear diagrams and practical problems fully worked out, but there are no exercises for the student to tackle. This seems a grave defect, presumably because the book is regarded as a work of reference, for the usefulness of a really excellent volume would have been considerably enhanced had the reader been provided with some good hard nuts to crack in addition to those already served up for him. A short index is provided, but there are no tables.

\section{Science and Reality}

By T. Bedford Franklin. Pp. vi+56. (London : G. Bell and Sons, Ltd., 1947.) 3s. 6d. net.

7 HE remarkable thing about this little book is that it has, in fact, been written. It is almost inconceivable that such would have been the case a few decades ago. The setting is a duologue between a man of science and Mr. X : the latter, by the way, is the late Sir Arthur Eddington's friend who knew what matter was. In a very nicely adjusted gam 9 of cut and thrust (much more charitable than usual) the crucial issue of materialism versus axiological precept is faced anew. The result is not altogether likely to convince where conviction is undesired (indeed there is little 'compulsion' anywhere), but the upshot is nevertheless indicative of humility, and therefore perhaps of progress towards a solution, or a partial solution, of mankind's greatest and deepest needs.

There are many quotations from leading scientific and philosophical writers : excellent as these extracts are, they tend on balance to weaken the argument. The author does not explicitly use them, and they resemble texts from which the preacher plans to escape as soon as possible. This, of course, is a wellknown technique; but the pages before us are robust enough to do without it.

The author's description of the usual biological theories could scarcely be bettered, though he is a little hard on their adherents when he expects them to produce precision without mechanism. This may indeed have to be done, but the day is not yet. Finally, one of the outstanding scholars whose work is quoted is inadequately described, not once but twice. Otherwise, the production is admirable.

F. IAN G. RAWLINS

\section{Atlas of Bacteriology}

By Dr. R. Cranston Low and T. C. Dodds. Pp. vii + $2+168$ plates. (Edinburgh : E. and S. Livingstone, Ltd., 1947.) 32s. 6d. net.

7 HIS is a companion to text-books on bacteriology 1 and intended primarily for use by medical students. Organisms and cultures have been reproduced mainly from actual colour photographs, with water colours when that process was unsatisfactory. The results are, on the whole, very good and a credit to the photographer, Mr. T. C. Dodds. Very brief descriptive notes accompany the illustrations. The book should be a useful visual aid to the study of bacteriology.
James Marshall 